\title{
Seaborne Petrochemical Spill Analysis Within the United States, 1992-1999
}

\author{
BENJAMIN L. NICHOLSON* \\ United States Coast Guard \\ Office of Congressional Affairs, 6-ICA \\ 2358 Rayburn House Office Building \\ Washington, DC 20515, USA
}

\section{ANASTASSIOS N. PERAKIS}

Department of Naval

Architecture and Marine Engineering

University of Michigan

2600 Draper Road, NAME Building

Ann Arbor, Michigan 48109-2145, USA

\section{JONATHAN W. BULKLEY}

Department of Civil and

Environmental Engineering and

School of Natural Resources and

Environment and

Center for Sustainable Systems

University of Michigan

430 East University, Dana Building

Ann Arbor, Michigan 48109-1115, USA
ABSTRACT / Through discussion of causative factors and examination of historical data, petrochemical spill prevention in US waters is reviewed. Unintentional petrochemical outflow is analyzed in a comprehensive manner and presented as a hierarchical sequence of antecedent events to reveal the trends of causative factors leading to release. Specifically, a seaborne petrochemical spill is examined in terms of four basic, antecedent events: (1) an underway source, (2) a failure incident, (3) a marine accident capable of breaching the hull and cargo block, and (4) the onset of outflow. These events are further subdivided into underlying, contributing events to form a causative framework for spill prevention. While a hierarchical review is not necessary to uncover the elements of causation, it does provide a comprehensive and logical structure that clearly defines these elements in terms of occurrence frequency and contribution to resulting outflow. It is found that relatively small, frequent spills less than 40,000 liters (10,567 gallons), attributable to human operator failures, leading to grounding, and cargo transfer system failure accidents, dominate US seaborne petrochemical outflow from 1992 to 1999. Given the frequency of groundings, structural reinforcement regulations such as those contained in the Oil Pollution Act of 1990 (requiring double hulls) appear well justified. However, passive restraint systems are secondary to the need for vigilant training and licensing of tank vessel operators.
Nations have typically addressed environmental issues in an ad hoc manner, striving to remedy a given crisis with reactionary, prohibitive policy (Woodward 2000, Yaffee 1982). Just as the sinking of the $H M S$ Titanic and the Three Mile Island nuclear incident prompted governmental action, the grounding of the Exxon Valdez and its subsequent release of 42 million liters (11 million gallons) of crude oil-the largest petrochemical spill ever in US waters-catalyzed the US Congress to pass historic legislation. US Public Law 101-380, the Oil Pollution Act of 1990 (OPA90), transformed petrochemical transport operations and their regulation within US waters by emphasizing pollution prevention and establishing a policy goal of "zero oil

KEY WORDS: Oil spills; Petrochemical outflow; Tank vessel accidents; Marine pollution prevention; Marine environmental protection

*Author to whom correspondence should be addressed. outflow" (similar to the zero discharge goal of Clean Water Act, P.L. 92-500).

OPA90 mandates new tank vessels to be of doublehull construction and requires the phase-out of singlehulled vessels no later than 2015 (OPA90's Title IV, $\$ 4115$; refer to the Springer website [http://www.link. springer-ny.com/link/service/journals/00267/index. htm] for additional information containing a synopsis of OPA90 requirements). Because groundings were the predominant accidents contributing to oil spills in 1990 [60\% of tanker spills (EST News 1999)] and because US ports are comparatively shallow by international standards [average depth of major US petrochemical

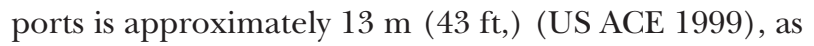
compared to an average depth of $23 \mathrm{~m}(75 \mathrm{ft})$, for major international petrochemical ports (Lloyd's 1999)], OPA90 mandated the implementation of the most proven design for this accident type while also considering the second most frequent hull-rupture mishap, collisions. 
While the double-hull design does provide a reduction in outflow probability, it only addresses a single element in the sequence of events that lead to an unintentional release of petrochemicals. Furthermore, current pollution databases often classify spill causation into a single categorical event—such as hull/machinery failure, grounding, collision, etc.-resulting from human error rather than comprehensively identifying the sequence of factors that lead to outflow. Since, "there has been little effort to characterize [the tank vessel] system as a whole and to determine the areas that offer the greatest potential for risk reduction, the National Research Council has determined that maritime safety as a whole could benefit from the increased use of quantitative and qualitative risk analysis" (USCG 1995).

Accordingly, this paper analyzes seaborne spills in a holistic manner as petrochemical outflow is considered the final outcome of antecedent events. This approach is based upon the premise that petrochemical spills are random occurrences to be modeled as a conditional sequence of events, otherwise known as a hierarchy. Therefore, the objective of this paper is to define the causative factors contributing to outflow and to identify the underlying sources of error and risk within the context of a hierarchical framework. This framework is intended to provide a more comprehensive perspective of a spill event. The result of this effort is to provide a tool for improving the allocation of pollution prevention resources and identification of areas that may require regulatory reform in order to meet the implicit and explicit objectives of OPA90.

\section{Seaborne Petrochemical Outflow in US Waters}

Although seaborne spills constitute less than $10 \%$ of the total annual marine petrochemical outflow, the subsequent impact can be catastrophic upon the ambient environment, (NRC 1991). Petrochemicals (crude oil, product, or some variation of petroleum-related cargo) are transported by sea via tank vessels-barges or ships. Rare, yet horrific outflows such as the 1989 Exxon Valdez oil spill punctuate the history of oil transport and its regulation within US waters and around the world (DuPont 1992).

OPA90's structural mandates can be characterized as a form of prohibitive policy in that they do not allow for any variation of vessel design other than what is specified within its $\$ 4115$. Two assumptions are generally made about prohibitive policy: (1) that it is based upon technical certainties and, (2) that it "limits [administrative] discretion, precluding any balancing of costs and benefits and excluding outside parties from influencing implementation" (Yaffee 1982). Rather than technical certainty, a range of alternative tank vessel designs based upon probabilistic outflow prevention is what has developed in the post-OPA90 era, leading to the establishment of a policy goal and regulatory standard of "zero oil outflow."

An underway oil tank vessel is initially modeled as a "system" subdivided into three phases: prevention, mitigation, and response. Each of these phases contains multiple event elements that sequentially evolve through a network comprised of prespill causation factors, accident-induced outflow, attempts to mitigate and stop outflow, and post-spill cleanup and response operations. Since the prevention phase includes multiple events that lead up to the onset of petrochemical outflow, a seaborne spill can be approached holistically, as an aggregate sequence of causative events. Therefore, to best prevent a seaborne spill, reliability and risk reduction techniques need to be applied for each causative event. To this end, spill prevention regulations must exhaustively address: (1) each of the individual elements of spill causation, (2) the risks associated with each causative element, and (3) the sequential relationship of these elements leading to unintentional outflow.

\section{Environmental Risk of Outflow}

\section{Definition of Environmental Risk}

Risk can be informally defined as a product of the probability of occurrence of a hazardous event and the magnitude of resulting, harmful consequences (NRC 1991). A seaborne petrochemical spill can be considered a hazardous event, as it is a release of a substance with the inherent ability to inflict harm upon the marine environment (often expressed in ecological and fiscal terms). Therefore, the magnitude of environmental risk can be defined as a product of the frequency of spills and the resulting, negative consequences (represented by outflow magnitude). The magnitude of outflow risk in US waters is directly influenced by multiple factors, including: vessel traffic patterns; vessel type; vessel design and construction; geographical, environmental, and meteorological conditions; limitations of navigational accuracy; and the uncertainties associated with human performance.

\section{Quantification of Outflow Risk}

The ratio of the volume of oil spilled per volume of oil transported may be the most compelling metric in the quantification of spill risk, in that it compares the consequences (outflow volume) with a normalized baseline (volume transported via tank vessels) (NRC 
1991). Based on USCG data for the period 1974-1978, the ratio for oil tankers is $3.3 \times 10^{-5}$ (33 liters lost per million liters transported) and for barges $1.7 \times 10^{-5}$ (17 liters spilled for every million liters shipped) (NRC 1991).

For the period 1980-1990, an average year included $9.5 \times 10^{6}$ liters $\left(2.5 \times 10^{6}\right.$ gallons $)$ of oil spilled and $6.4 \times 10^{11}$ liters $\left(1.7 \times 10^{11}\right.$ gallons $)$ transported via all tank vessels within US waters (NRC 1991). These figures yield a spill-to-transport ratio of $1.5 \times 10^{-5}$ or an average of 15.0 liters of oil spilled for every million liters shipped within US waters (NRC 1991).

For the period of 1992-1999, the average yearly volume of petrochemicals spilled in US waters from all tank vessels (barges and tankers) was $21.7 \times 10^{5}$ liters $\left(5.7 \times 10^{5}\right.$ gallons $)$ while the average yearly volume of petrochemicals transported in US waters by all tank vessels was $10.5 \times 10^{11}$ liters $\left(2.8 \times 10^{11}\right.$ gallons $)$ (Dickey 1999). This yields a spill-to-transport ratio of $2.1 \times$ $10^{-6}$ or 2.1 liters of petrochemicals spilled for every million liters transported (D. Dickey Personal Communication).

Since the enactment of OPA90, the USCG has found (NRC 1998): The average number of oil spills over 40,000 liters (10,567 gallons) has dropped by approximately 50\% from pre-1991 levels. Liters spilled per million liters shipped has been reduced from an annual average of 10 liters spilled per million liters shipped for the years 1987-1990 to 5 liters spilled per million liters shipped during the years 1991-1997-a 50\% decrease. For the period of 1992-1999, this number has dropped even further to 2.1. There have been no spills greater than 4 million liters (approximately 1 million gallons) since 1990 .

The significant decrease in petrochemical outflow cannot be attributed to the advent of a mandatory double-hull design under OPA90. It is logical to presume, however, that the decrease in accidental spillage from tank vessels since the Exxon Valdez accident is a function of numerous efforts to improve marine pollution prevention, including expanded spill liability provisions under OPA90 as well as the negative marketing implications of environmental degradation.

\section{Examination of Spill Components}

In order to examine the individual elements of a spill, it is assumed that there are a finite number of event paths that can lead to the occurrence of unintentional petrochemical outflow. The analysis of such an event must begin with a source of petrochemical cargo. An underway oil tank vessel transiting US waters is considered the initial event of the seaborne spill sequence for the purposes of this paper.

\section{Source of Outflow}

To improve the reliability of tank vessels, OPA90 included a double-hull mandate within Title IV, $\$ 4115$. Because of the substantial costs and operational uncertainties associated with the double-hull design, there has been considerable controversy over this regulation.

In 1992, the USCG conducted an extensive technical analysis to assess alternative designs that could potentially improve maritime safety and environmental protection (North 1999). This analysis found that the single-hull design (Figure 1A) was inadequate in terms of outflow prevention (NRC 1991, IMO 1997). The double-hull and mid-deck designs (Figure 1F) were found preventatively superior in all cases (NRC 1991, IMO 1997). The International Maritime Organization (IMO) specifically recognized the mitigation attributes of the mid-deck design through the implementation of Regulations 13F and G of Annex I of the International Convention for the Prevention of Pollution from Ships, 1973/78 (MARPOL), equivalently endorsing the double-hull and mid-deck designs through a quantitative pollution prevention index scale (IMO 1997).

The USCG interpreted OPA90 such that the doublehull was mandated to prevent oil outflow. "Therefore, when evaluating potential alternatives, the USCG's premise was that a vessel's 'zero oil outflow characteristics' and quantity of mean and extreme outflow could not be balanced against each other" (North 1999). This rationale was further justified by the wording of the US Clean Water Act (CWA) stating, "Congress hereby declares that it is the policy of the United States that there should be no discharges of oil or hazardous substances into or upon navigable waters of the United States" (North 1999). It was then determined that any tank vessel design alternative must have a probability of zero oil outflow, for both collisions and groundings, equal to or better than that of a double-hull. The USCG concluded (North 1999): the double-hull design was the most effective in preventing the majority of oil spills; no design could prevent significant outflow under a severe accident scenario; and no alternative design could be endorsed as equivalent or superior to the double-hull.

As previously noted, the authors do not presume that the double-hull design is responsible for the notable decrease in accidental petrochemical outflow over the last ten years. Rather, the revised regulatory composition of OPA90, combined with the substantial increase in public perception with regard to corporate environmental stewardship, are the most likely factors 


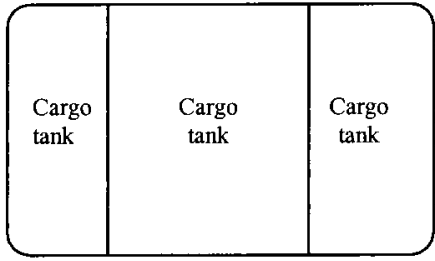

Figure 1.A: Single-hull tanker

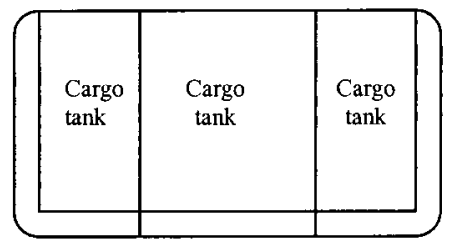

Figure 1.C: Double-hull tanker with Jtank configuration

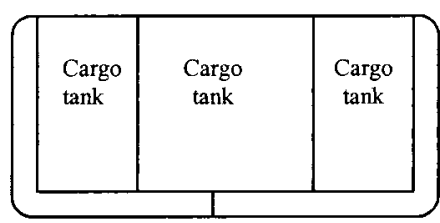

Figure 1.E: Double-hull tanker with L-tank configuration

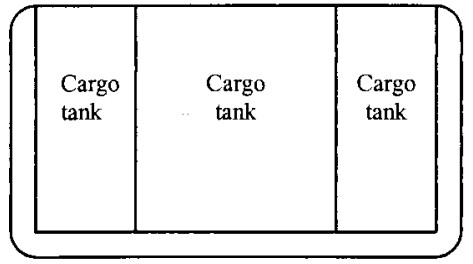

Figure 1.B: Double-hull tanker with Utank configuration

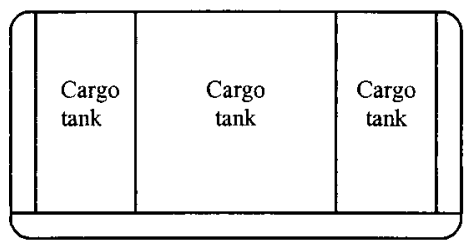

Figure 1.D: Double-hull tanker with Stank configuration

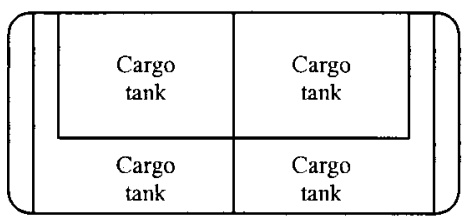

Figure 1.F: Mid-deck tanker configuration with double sides

Figure 1. Various oil tanker design mid-ship sections; three cargo tanks across (NRC 1991).

that have contributed to improved environmental performance of tank vessels.

Two pending studies are examining the double-hull issue. The Marine Board and US Department of Transportation initiated a study of double-hull alternatives to establish an equivalency evaluation procedure that not only maintains a high standard of environmental protection, but also encourages more innovative designs (North 1999). Secondly, the USCG-chaired Ship Structure Committee and the Society of Naval Architects and Marine Engineers have initiated a study intending to technically evaluate design performance and address the issue of fire and explosion hazards within the double-hull void space.

\section{Failure Incident Contributing to Outflow}

The next event in the sequence leading to seaborne outflow is a failure incident that links the point of origin (source) to the hull rupture-inducing accident and the subsequent unintentional release of petrochemical cargo. While the tank vessel carries the hazardous cargo, it is the unintentional failure of operations or the occurrence of an extreme event-human, mechanical, or otherwise-that leads to an accident capable of breaching the vessel's hull and cargo block.
Human operator error. The most common failure incident within the sequence of events leading to a seaborne oil spill can be associated with the human component of the tank vessel system. Between $60 \%$ and $80 \%$ of oil discharges can be attributed to some form of human operator error (USCG 1995, Ornitz 1997). The severity of those errors and the actions that follow are the key factors in the extent of pollution caused by an operator-error-induced spill. While it is apparent that operator errors will always occur, the goal is to eliminate the unrecoverable errors that lead to a total system failure. The study of operator reliability includes advanced training and licensing programs for personnel (USCG 1993), ergonomic design innovations (ABS 1998), human reliability analysis (HRA), and comprehensive pollution prevention plans such as the USCG's Prevention Through People (PTP) program (USCG 1995, Card 1995).

Mechanical failure. The transportation of petrochemicals by sea relies upon the function of mechanical devices. The failure of propulsion, steering, power generation, or cargo transfer system devices can prove disastrous for a vessel that depends on such mechanisms to maintain positive control. The application of reliability evaluation techniques is used to not only 
predict common modes of failure, but also to facilitate safer system designs (Billinton 1992). All nonmaintained mechanical systems will eventually fail; however, it is the understanding of the nature of failure and its probability that assists in the improvement of system reliability.

Navigational system failure. Navigational system failures not attributable to human operator error are extremely rare. These failures result from contact with an uncharted object, using a misplaced aid to navigation, a sudden system or component failure (i.e., satellite failure), or some other type of unforeseen failure beyond the control of the vessel's piloting team. Prudent navigation calls for redundancy; however, reliance upon failed components can obviously induce severe maritime casualties. The USCG estimates the US aids-tonavigation system to be better than $99.7 \%$ reliable and the US Air Force estimates the satellite-based global positioning system (GPS) to be at least $99.0 \%$ reliable (USCG NAVCEN 1999).

Extreme weather. Because "the outstanding characteristic of the open ocean is its irregularity," the marine environment poses a dynamic problem to both the naval architect and mariner in the prevention of weather-induced casualties (Beck and others 1989). The uncertainties associated with sea conditions compel designers and operators to probabilistically and statistically account for extreme weather-leaving room for error and anomalies.

\section{Marine Accident Contributing to Outflow}

Following the failure incident, the next event is the occurrence of a marine accident or casualty. To achieve open communication between the sea and the tank vessel's petrochemical cargo, a breach of the vessel's cargo containment integrity must result from one of the following types of marine casualties: grounding, collision or allision, fire/explosion, structural failure, or cargo transfer system failure.

Grounding. A grounding accident may be defined as the unintentional contact of a ship's hull with the ocean floor; this includes any protrusions or objects that encompass the ocean's bathymetric landscape. The double-bottom and double-hull designs are intended to provide for additional protection against grounding (NRC 1991). In addition, the USCG has initiated regulations for minimum under-keel clearance based upon given climatic and geographic conditions to further reduce the occurrence of this type of accident (OSIR 1996).

Collision/allision. The event of two vessels impacting one another is defined as a collision, while the contact of one vessel with a stationary object, such as a dock or pier, is referred to as an allision. While a grounding is a function of one vessel's actions, a collision is much more complex as it involves the combined actions of two independent vessels, their piloting teams, and risks associated with their respective cargo. An allision can be thought of as an event similar to a grounding in that one object is fixed and the causative factors lie solely within the vessel (assuming the object is not improperly placed within a navigable waterway). Thus, the complexity of a collision/allision is derived from the multiple inputs to the accident scenario; predominantly relating to the human operator's interface with the navigational system.

Fire/explosion. Shipboard fires and explosions constitute another type of accident that can potentially induce petrochemical outflow. Onboard an oil tank vessel, the combination of electric and mechanical equipment with potentially volatile cargo and fuel creates an omnipresent risk of fire or explosion (Gentile and Dickenson 1995). Moreover, a fire onboard a vessel is especially hazardous in that there is no immediate assistance available other than what can be provided by shipboard fire extinguishing systems and the efforts of the crew. The destructive potential of fires explains why these accidents often lead to oil outflow and sinking. Proper response training and the incorporation of shipboard fire protection systems are the means by which this type of accident can be mitigated to prevent degradation of the hull's integrity.

Structural failure. A failure of the ship's hull structure can create open communication between cargo and sea. If the ship's structure is not properly maintained and certain climatic conditions exist, the integrity of the vessel can be compromised. Therefore, intensive structural reliability techniques are incorporated within the vessel design process. In addition, the shift in emphasis to oil outflow reduction and elimination has included design improvements to the subdivision structure of the cargo hold (Daidola 1995). Refer to Figure 1 for example cross-sectional diagrams of subdivision structures (three tanks across).

Cargo transfer/containment system failure. One of the most common types of accidents contributing to a seaborne petrochemical spill is that of a failure or malfunction of the tank vessel's cargo transfer or containment system (including the piping network, valves, control devices, etc.). Proper training of the cargo system operators as well as reliability-based design is the means by which these accidents are either reduced or eliminated. 


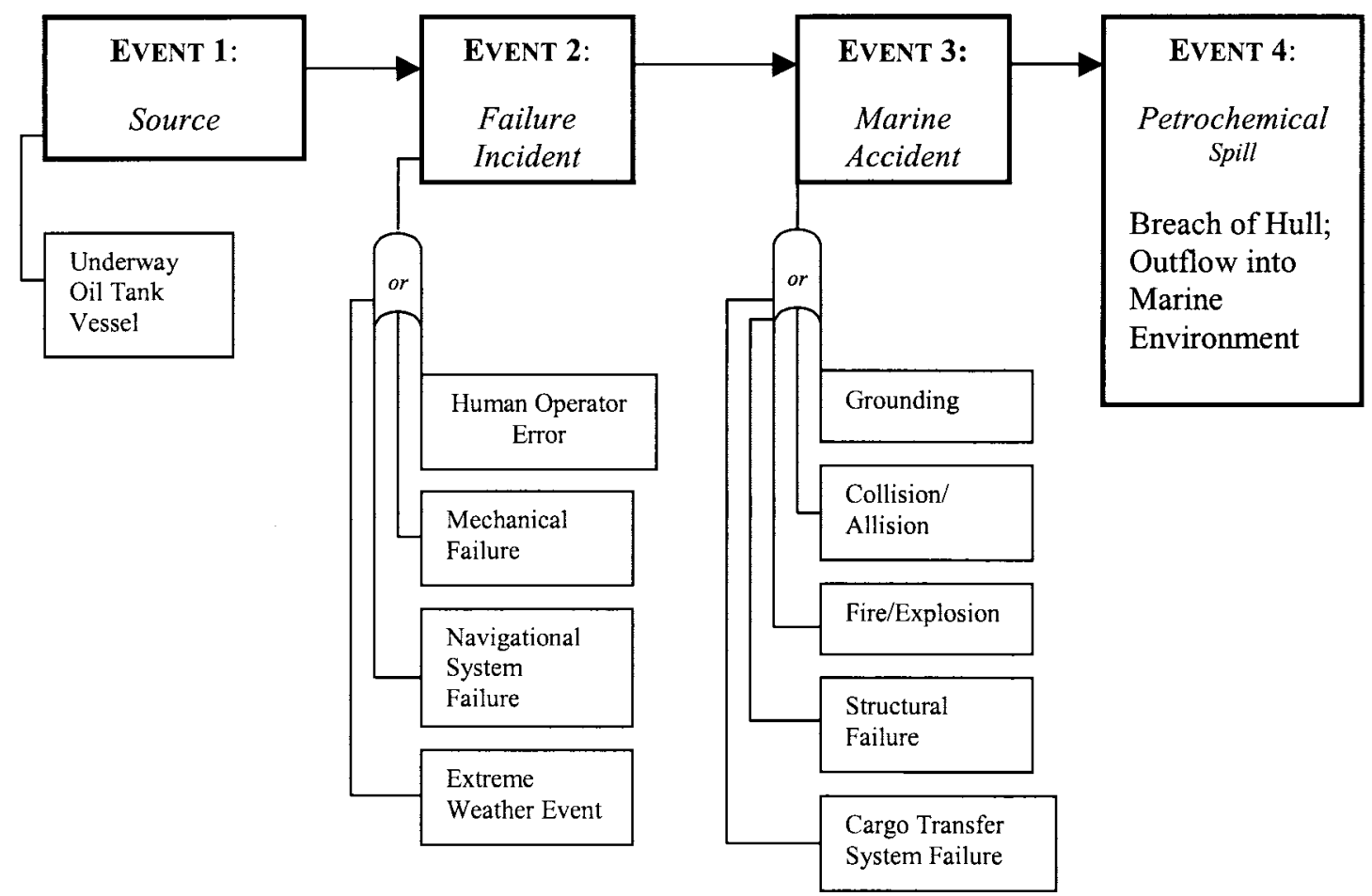

Figure 2. Hierarchical block diagram for prevention phase of a seaborne petrochemical spill.

\section{Unintentional Outflow}

The result of the marine accident is a breach of hull and cargo block, thus leading to outflow. Once the integrity of the hull and cargo block is compromised, free communication between petrochemical cargo and the sea exists. The rupture of the hull instigates a phase transition within the analysis of an oil spill from one of prevention to one of mitigation as well as response. At this juncture, outflow reduction and stoppage take the place of preventative actions.

\section{The Causation Hierarchy}

Although systems are commonly modeled as a sequential combination of events, most systems are, in fact, hierarchical in nature-a conditionally dependent sequence of antecedent events that causes a larger, more severe event. The analysis of petrochemical outflow data for the period 1992-1999 is approached as a systematic decomposition of a complex event into its contributory components. This approach aims to clearly define the possible causative elements and the sequential pathways comprised of these elements that lead to the larger, more complex event, hence, the term "hierarchical." The intended result is an explicit framework characterizing the sequential distribution of causative elements for a large-scale event in terms of occurrence frequency and consequence contribution (Figure 2).

Because of the direct relationship between the causation and prevention of a seaborne pollution event, the systematic analysis of outflow causation is beneficial and necessary to the attainment of the USCG's goal of zero oil outflow. By analyzing a spill event as a hierarchy, one can clearly define: the possible causative factors contributing to a spill, the historical frequency and severity distribution of those factors, and the historical frequency and contributing severity distribution of the sequential, causative pathways leading to a spill event.

The prevention of petrochemical outflow through the examination of singular events is limited due to the randomly dependent association between the elements that sequentially lead to spillage (involving the sequence both to and from the individually contributing events). This limitation, combined with the NRC's assertion stressing the need for additional risk analysis techniques and comprehensive study, led to the hierarchical analysis of available petrochemical outflow data from 1992 to 1999 . To this end, seaborne petrochemical outflow is approached holistically, as a hierarchical aggregation comprised of sequentially dependent, antecedent events-each with an inherent 
probability of occurrence-that contribute to the causation of a spill.

Although human operator error has continued to be the predominant contributory event leading to a hullbreaching accident that results in petrochemical outflow, it is not the definitive "cause" of a given spill scenario. For example, while a collision between two vessels may lead to a petrochemical spill event, it is the compromise of the hull and cargo block, allowing open communication between cargo and sea, that actually causes the spill. All collisions do not result in outflow; therefore, the cause is the rupture of the cargo tank's integrity as a result of a collision. A collision must be preceded by antecedent events (a spill-inducing accident can not just happen without preceding events occurring, such as a navigational error, human operator error, or a machinery failure). The distribution of causative factors-those events preceding and leading to the spill-inducing accident-and the various types of hull rupture accidents are not revealed unless a systematic study of marine operations and historical accident data is conducted.

\section{Data Integration}

Recent petrochemical spill data obtained from the USCG's Marine Safety Information System (MSIS) database (Dickey personal communication) is applied to the framework to examine the modern causation patterns of accidental outflow. Specifically, the occurrence frequency of each event element and the resulting consequences-in terms of outflow magnitude-are examined. The data quantifies each event component and the associative links to and from the preceding and following events, thus allowing for a comprehensive examination of pathway frequency through the hierarchical framework and the resulting outflow consequences.

Because OPA90 changed the way tank vessels conduct the transport of petrochemicals through US waters and the manner by which environmental regulators approach related violations, the passage of this legislation can be considered the modern benchmark for US petrochemical spill analysis. Therefore, petrochemical spill analysis within US waters can be divided into two periods: the pre-OPA90 era and the post-OPA90 era. Although 1990 marks the passage of OPA90 into law, the majority of its programs were not implemented until 1992. Therefore, the post-OPA90 era is defined as the period since its mandates were active, or 1992 to the present. This paper specifically focuses on the period of 1992-1999 to characterize the recent distribution of petrochemical spill causation within US waters. How- ever, for the purpose of background comparison, an overview of the pre-OPA90 era is also provided.

The pre-OPA90 era. During the 1950s and through the early 1970s, tank vessels grew considerably in terms of cargo capacity due to technological shipbuilding improvements and economic necessity. Due to the draft of these vessels, the USCG lobbied the IMO to impose the requirement of double bottoms on tank vessels to provide for additional protection against groundings. This design was effectively rejected on the basis that the majority of the world consisted of deep ports in which collisions were a greater risk than groundings. US waters are comparatively shallow by international standards and the majority of spills were attributable to groundings. Thus, the environmental issues pertaining to petrochemical transport in US waters did not align well with the concerns of the international community and the IMO.

Although the double-hull tank vessel design had been developed in the late 1960s, most oil tank vessels were of single-hull construction. Although some oil companies utilized double-hulled vessels, the increased costs, maintenance, and operational complexity of this design prevented them from ever becoming an industry standard. As of 1991 approximately $79 \%$ of the world's tank vessels had single hulls (NRC 1991).

The distribution of marine accidents contributing to outflow prior to the passage of OPA90 is given in Figure 3 (NRC 1991). The data available for the pre-OPA90 period draws a distinction between barges and tankers; thus, Figure 3 only refers to accidents of oil tankers that are $\geq 10,000$ dead weight tons (DWT). Furthermore, the data do not include cargo transfer system failures.

The examination of this pre-OPA90 data reveals a relative dominance-in terms of both frequency and share of resulting outflow- of groundings in the distribution of marine accidents contributing to spills within US waters. The relatively shallow US ports and waterways, combined with the statistical dominance of groundings, brought the double-hull requirement issue to the forefront of US maritime regulation. The 1989 Exxon Valdez and the 1990 American Trader (1.5 million liters or 394,000 gallons of outflow off the southern California coast in February 1990) oil spills provided the final justification for unanimous Congressional support.

The post-OPA90 era. Ten years after the Exxon Valdez spill, it is apparent that this accident and OPA90 have set the tone for the petrochemical shipping industry. The opponents of OPA90 continue to argue that it does not consider the best interests of the marine environment as it enlists only one, principal type of technology that is primarily aimed at spill prevention, thus ignor- 


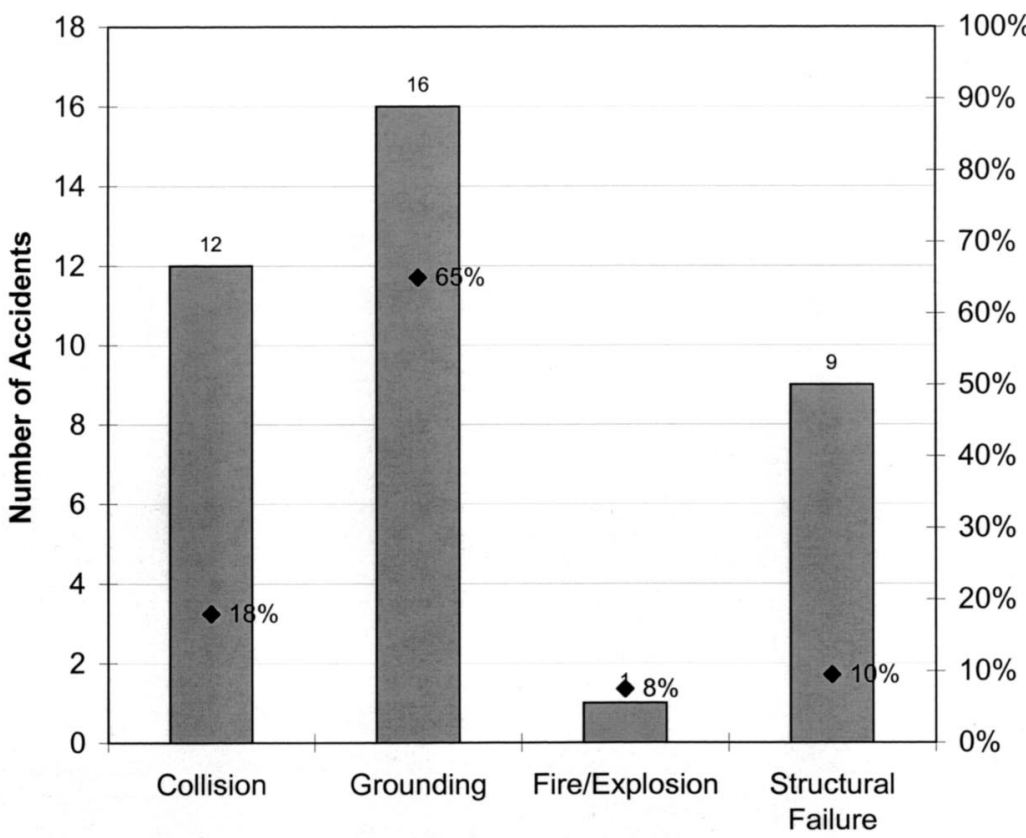

$100 \%$

$90 \%$

$80 \%$

$70 \%$

$60 \%$

$50 \%$

$40 \%$

$30 \%$

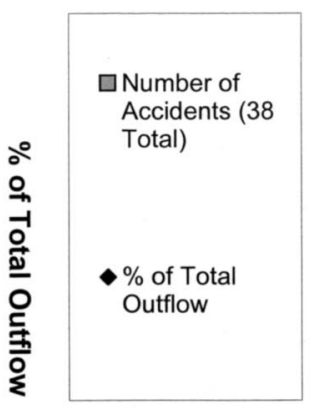

$20 \%$

$10 \%$

$0 \%$

Failure

Figure 3. Accident distribution for major petrochemical spills $>40,000$ liters $(10,567$ gallons) in US waters. 1980-1990 (NRC 1991).

ing the other phases of a spill event: mitigation and response. The question remains whether the USCG will equivalently recommend alternative designs in concert with IMO. The wording of the applicable US laws is very specific and leaves the burden of such a recommendation upon the USCG.

The analysis of spill causation is approached under specified conditions. All spills could be considered human error in that a tank vessel carrying petrochemicals would not exist without human intent. This rationale refers to the expression "we could eliminate all humaninduced environmental problems if we just remove the humans." Obviously, this is not a practical approach. In this study, we define "human operator error" as an element of failure, not the absolute source. By this distinction, we conclude that mechanical equipment failure and navigational system failure can be attributable to human behavior as well as random occurrences. Moreover, extreme weather events can be attributed to meteorological error (an error in prediction or interpretation), lack of due care by the operator, or a random unforeseen act of nature (more rare and severe than the proverbial "100-year storm").

Data for 1992-1999 was extracted from the USCG MSIS database (Dickey personal communication). This criterion-based search combined all seaborne tank vessels and included all reported petrochemical outflows of $\geq 39800$ liters (1000 gallons) within US waters (161 total spills). Furthermore, the data include cargo transfer system failures, as it is one of the most frequent accidents leading to unintentional outflow. First, the data are presented in graphical form, but the precepts of the hierarchical framework are also applied. Two queries of the USCG MSIS database were run, such that the distribution of marine accidents and preceding failure incidents were extracted independently with respect to frequency and consequence. From the MSIS database, there were 137 discernible accident classifications with regard to failure incidents and marine accidents out of the 161 total reported spills. The results of these queries are presented in Figures 4 and 5 (for additional post-OPA90 era data, including geographical distribution of outflow in US waters, refer to the additional information and data listed on the Springer website [http://www.link.springer-ny.com/link/service/ journals/00267/index.htm]).

The answer to the question, "what causes a seaborne petrochemical spill from a tank vessel in US waters during the post-OPA90 era" is revealed once the antecedent events are examined in a hierarchical context. A spill event is holistic in that it is a large event comprised of multiple antecedent events. Upon closer examination, however, it is also hierarchical in that the outcome of one event determines the occurrence of the next, sequentially dependent event. The extracted data results are presented in a hierarchical context in Figures 


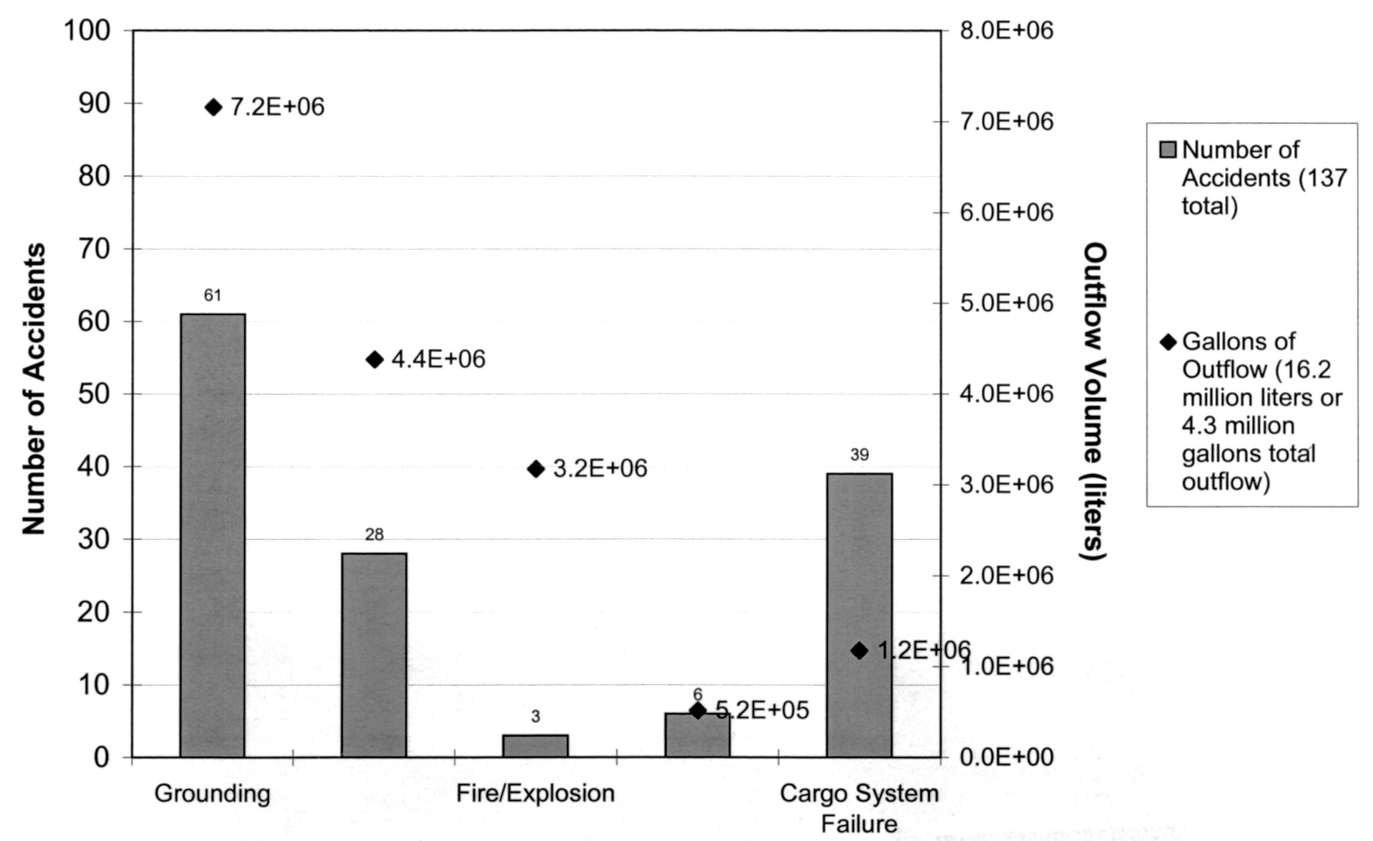

Figure 4. Marine accidents contributing to seaborne petrochemical spills >3800 liters (1000 gallons) in US waters, 1992-1999; Source USCG (D. Dickey personal communication)

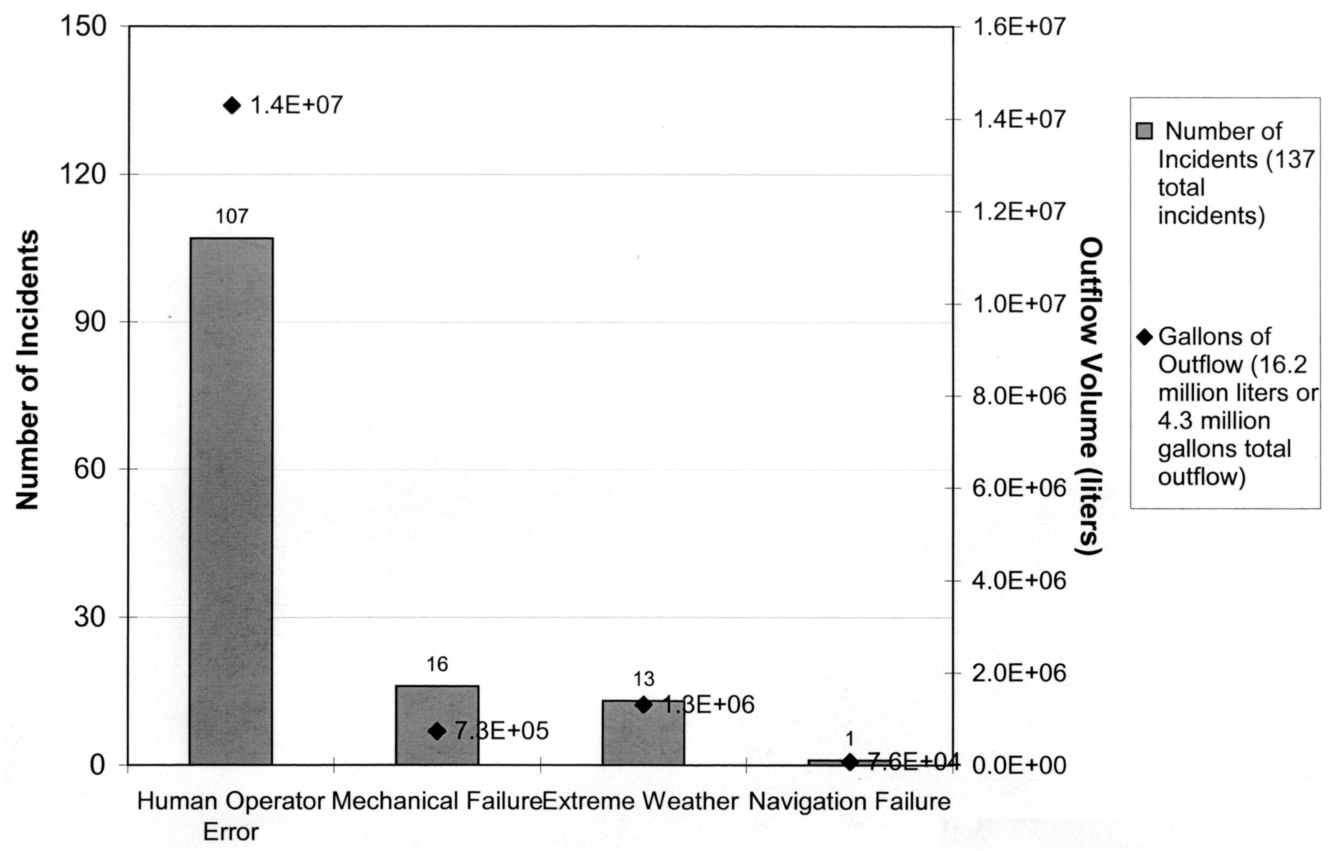

Figure 5. Failure incidents contributing to seaborne petrochemical spills $>3800$ liters (1000 gallons) within US Waters, 1992-1999; Source USCG (D. Dickey personal communication)

6 and 7 with respect to occurrence frequency and consequence severity (outflow magnitude), thus defining spill causation and characterizing the risk of petro- chemical outflow in terms of the aggregated risk of the individual causative elements.

Within Figures 6 and 7, the most frequent and 


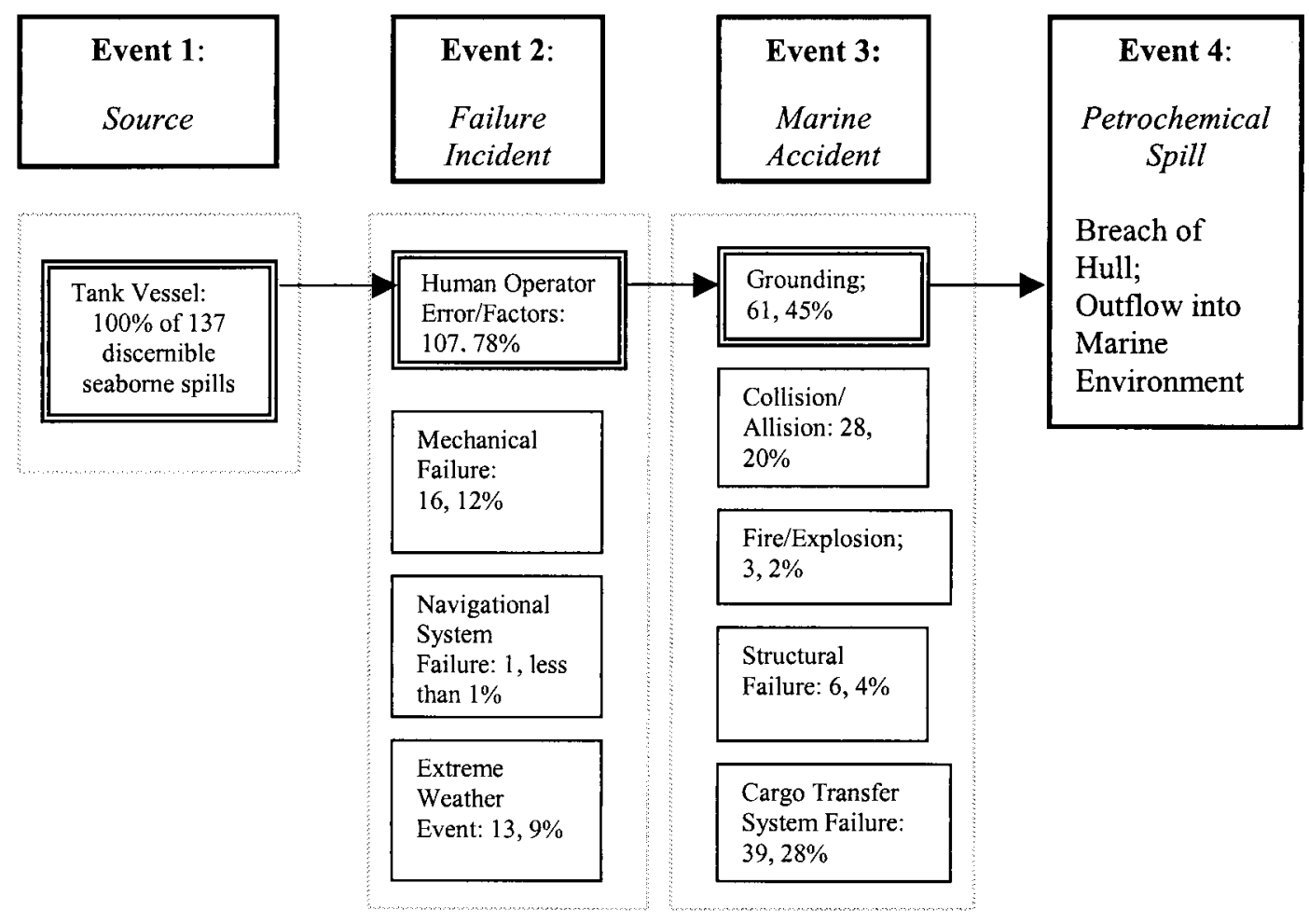

* Out of 161 total, reported spills greater than 1,000 gallons from 1992-99, only 137 classifications were discernable for marine accidents and failure incidents.

Figure 6. Prevention phase of a seaborne petrochemical spill: frequency of occurrence and percent of total events, $1992-1999$.

most consequential paths are highlighted. In both cases, the pathway leading from the source to human operator error and on to the grounding accident are the most frequent and most severe. However, Figure 6 , it is apparent that cargo transfer system failures are also significantly frequent. There Also is relative parity among the resulting outflow volume between groundings, collisions, and fire/explosions.

The dominance of human operator error justifies an even greater allocation of resources to this causative element. The frequency and consequence of grounding accidents further validate the structural reinforcement of tank vessel bottoms in US waters. However, it is notable that considerable outflow volumes also originate from both collisions and fires. While the occurrence frequency of fires and explosions is very low $(2.2 \%)$, the outflow volume is rather significant in that it accounts for $19.3 \%$ of the total outflow volume in US waters from 1992 to 1999. This occurrence-to-outflow ratio is very telling and must be considered along with the more apparent causation patterns noted above. In the case of fire/explosion, this ratio is a significant 1.1 million liters
(279,500 gallons) of outflow per occurrence. However, this ratio merely examines the average outflow per occurrence; it does not indicate the distribution of events with regard to the resulting outflow volume. The magnitude of this particular ratio is driven by one very large outflow event of over 3 million liters (800,000 gallons).

The occurrence frequencies of failure incidents and marine accidents with respect to the resulting outflow volume are graphed in Figures 8 and 9. These figures reveal that while large outflow volumes continue to occur, the post-OPA90 era is dominated by small, frequent spills attributable to groundings, cargo transfer system failure accidents, and human operator failure incidents. However, the other causative factors also correlate to noteworthy outflow volumes despite being less frequent. The occurrence-tooutflow distributions in Figures 8 and 9 form a quantitative foundation for the probabilistic modeling of each causative event. From these results, probability density functions (PDFs) can be established for random variables representing outflow per causative factor. 


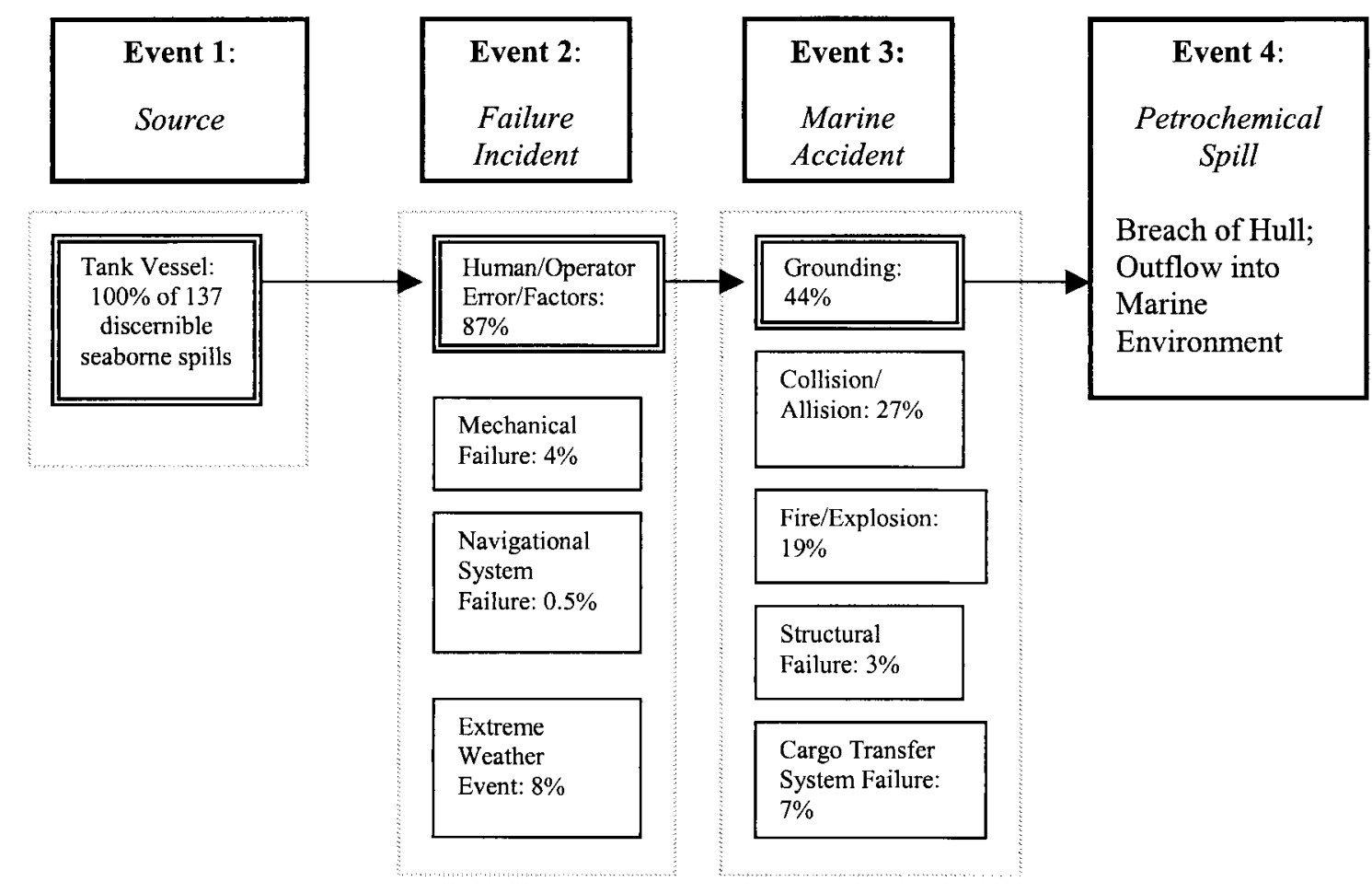

* Out of 161 total, reported spills greater than 1,000 gallons from 1992-99, only 137 classifications were discernable for marine accidents and failure incidents.

Figure 7. Prevention phase of a seaborne petrochemical spill: consequence of occurrence (percentage of total resulting outflow, 1992-1999).

\section{Conclusion}

Petrochemical spills are hierarchical in nature. A spill event cannot occur without the hierarchical progression of antecedent events including an underway source, an enabling failure incident, and a marine accident capable of breaching the integrity of a vessel's cargo containment structure. While a hierarchical presentation of data is not necessary to uncover the major elements of causation, it does provide a logical and organized framework for analysis. The principal outcome of this research is a more robust understanding of petrochemical spill causation in the post-OPA90 era.

The hierarchical presentation of the frequency and severity of significant outflow events reveals the distribution of the causative pathways leading to petrochemical outflow. Relatively small, frequent outflows $>40,000$ liters (10,567 gallons) attributable to human operator failure incidents, leading to grounding and cargo transfer system failure accidents, dominate these distributions. Given the shallowness of US waterways and the prevalence of grounding accidents, a double bottom structure appears necessary to effectively re- duce unintentional cargo outflow. Therefore, structural regulations such as OPA90's \$4115 appear well justified. However, it also apparent that a passive restraint system is secondary to the vigilant training of tank vessel personnel in an attempt to minimize and eliminate human operator errors that contribute to outflow.

Environmental degradation resulting from human error is not surprising or uncommon. The results of this research demonstrate that despite advances in error prevention and prohibitive policy, significant unintentional outflows continue to occur. However, the results also show marked improvement in terms of decreasing frequency and volume of spill events. The preliminary survey research that was the basis for this paper found that for each and every element of the causative framework, preventive initiatives are either in place or being developed. The majority of these preventive programs-which were found to be exhaustive and rigorous in nature- focus upon the human element of the vessel system. Simply put, a tank vessel carrying petrochemical cargo cannot occur without hu- 


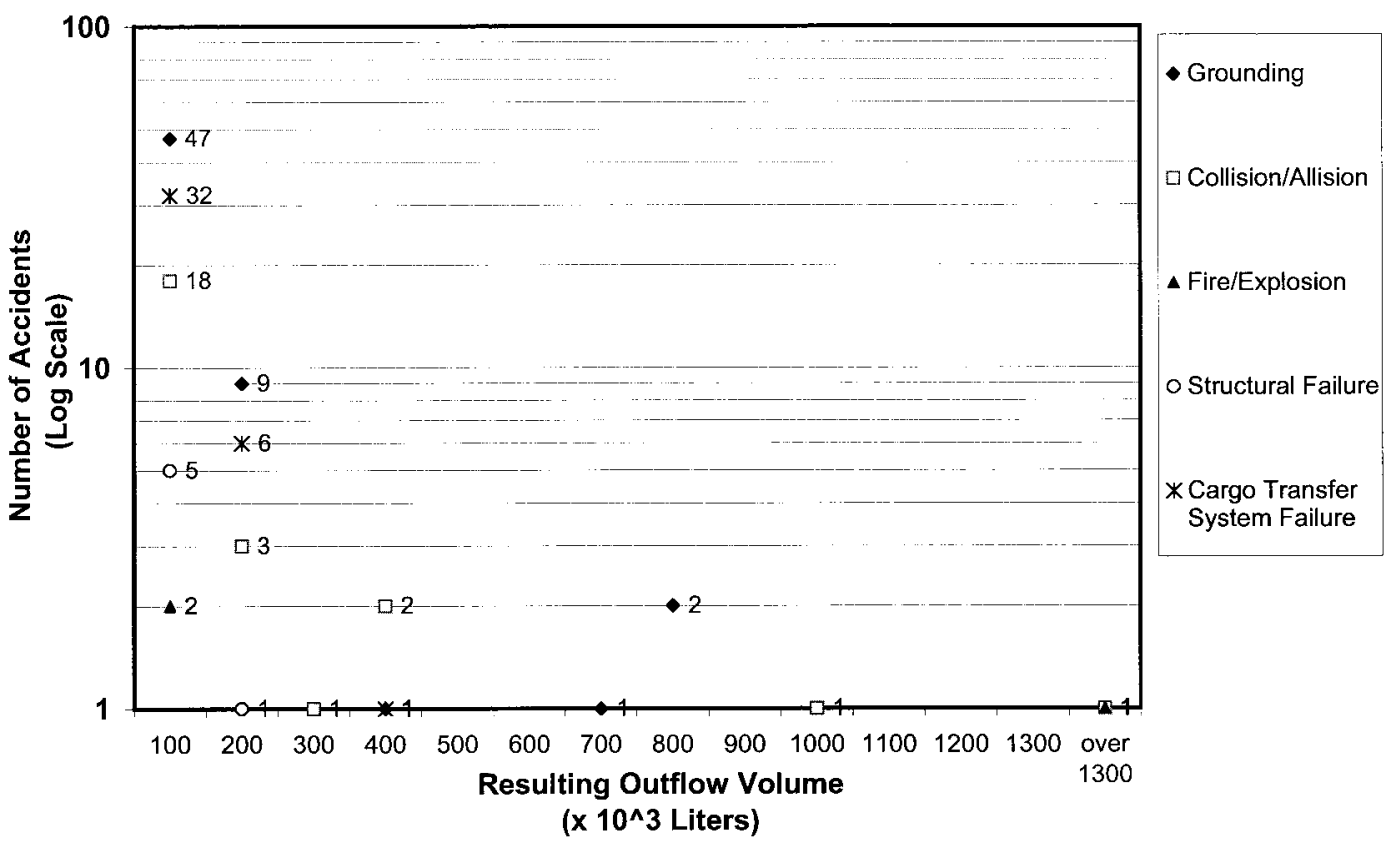

Figure 8. Distribution of marine accidents resulting in seaborne petrochemical outflows $>3800$ liters (1000 gallons) in US waters, 1992-1999; source USCG (D. Dickey personal communication).

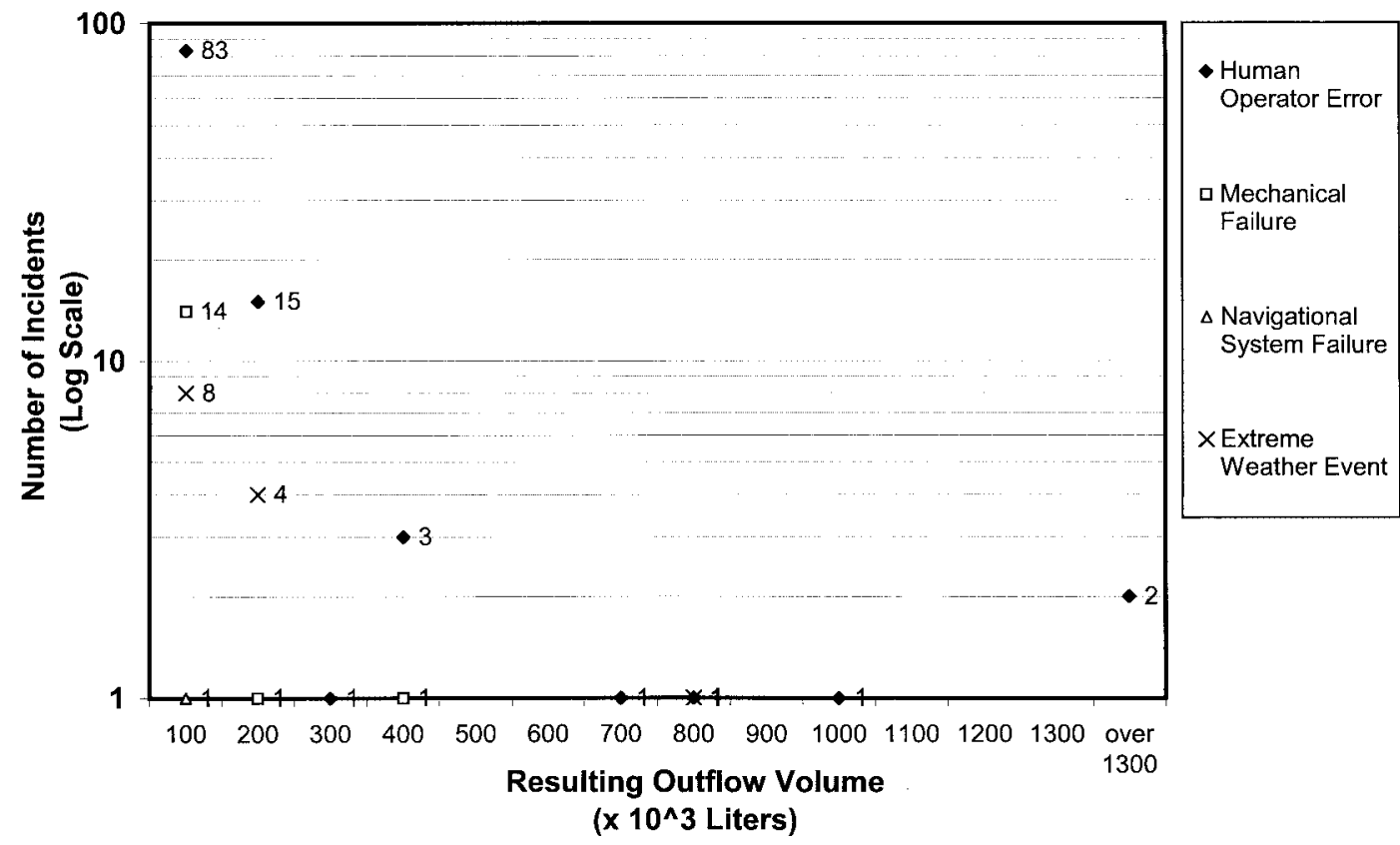

Figure 9. Distribution of failure incidents resulting in seaborne petrochemical outflows $>3800$ liters (1000 gallons) in US waters, 1992-1999; source USCG (D. Dickey personal communication).

man intent; therefore, human operators are ultimately and inescapably responsible for their vessel. While this paper does identify other causative pathways that lead to outflow, the preponderance of data pointing to human error alludes to the need for greater environmental stewardship on behalf of the petrochemical trans- 
port industry. It is counter to the interests of all parties involved for unintentional outflow to occur, as it not only leads to environmental damage detriment, but also decreased revenue. This dynamic appears to be the primer within the debate regarding the environmental implications of petrochemical spills as it fosters a collaborative approach to superior environmental performance of tank vessels and, ultimately, the elimination of cargo loss.

Further research is needed in the mitigation and response phases of petrochemical outflow. Incorporating these two phases in the hierarchical context would allow for a more comprehensive analysis of outflow from source to response completion and environmental impact assessment. While OPA90 focuses primarily on prevention and response, more research is needed on not only the intermediate phase of mitigation, but also on the holistic examination of the spill event from source to response conclusion. This would include a more thorough examination of accidents that not only result in petrochemical outflows, but also those that do not result in spillage in order to more accurately model the conditional nature of each of the causative elements.

Finally, it is the opinion of the authors that pollution response and reporting personnel should incorporate a hierarchical approach in the classification of marine casualties, as many pollution incident classifications were not thoroughly indicative of the nature of outflow. Spills should be classified methodically, by each of the causative factors that contribute to the outflow.

\section{Authors' Note}

The acceptance of this paper and subsequent revision occurred during a massive overhaul of the Coast Guard's Marine Safety database and data management system. Numerous changes have been made to the Marine Safety Information System (MSIS); this system has been replaced by a new data management system that also includes law enforcement and intelligence information. As part of this new database, the causative factors associated with a marine casualty are listed in a more comprehensive and sequential manner. The statements contained in this paper are those of the authors; they are by no means a reflection of official Coast Guard or United States policy.

\section{Acknowledgments.}

Mr. David Dickey of the US Coast Guard's Marine Operations and Analysis Division is acknowledged for his provision of spill data and access to the USCG MSIS database. Mr. Jaideep Sirkar and Lieutenant Commander Tom Miller of the US Coast Guard's Marine Safety Naval Architecture Division are acknowledged for provision of references and regulatory information.

\section{Literature Cited}

ABS (American Bureau of Shipping). 1998. Guidance notes on the application of ergonomics to marine systems. New York, 73 pp.

Beck, R. F., W. E. Cummins, J. F. Dalzell, P. Mandel, and W. C. Webster. 1989. Motions in waves In Principles of naval architecture, Volume III: motions in waves and controllability. Society of Naval Architects and Marine Engineers (SNAME). Jersey City, New Jersey, 188 pp.

Billinton, R., and R. N. Allan. 1992. Reliability Evaluation of Engineering Systems: Concepts and Techniques. Plenum Press, New York, 453 pp.

Card, J. C. 1995. Prevention through people. 60 Federal Register 3288. January.

Daidola, J. C. 1995. Tanker Structure Behavior During Collision and Grounding. Marine Technology 32: 20-32.

DuPont, D. A. 1992. The double-hull requirement: the tanker industry's influence on pollution prevention design standards. Master's thesis. University of Washington School of Marine Affairs, 118 pp.

EST News (Environmental Science and Technology News). 1999. Technology gaps exacerbate vulnerability to heavy oil spills. Environmental Science and Technology 00: 149A.

Gentile, M. J., and R. P. Dickenson. 1995. Casualty data analysis of the world merchant fleet for reported fire and explosion incidents resulting in marine pollution. US Department of Transportation, Research and Special Programs Administration Report. Performed by John A. Volpe National Transportation Systems Center; sponsored by the US Coast Guard Office of Marine Safety and Environmental Protection. Washington, DC, $53 \mathrm{pp}$.

IMO (International Maritime Organization). 1997. MARPOL $73 / 78$, consolidated edition 1997. Articles, protocols, annexes, unified interpretations of the international convention for the prevention of pollution from ships, 1973, as modified by the Protocol of 1978. London, pp. 39-222.

Lloyd's (Lloyd's Shipping Information System). 1999. International port statistics furnished to United States Army Corps of Engineers. Lloyd's Register. London.

NRC (National Research Council, Committee on Tank Vessel Design). 1991. Tanker spills: prevention by design. National Academy of Sciences, National Academy Press, Washington, DC, 350 pp.

NRC (National Research Council, Committee on Tank Vessel Design). 1998. Double hull tanker legislation: an assessment of the oil pollution Act of 1990. National Academy of Sciences, National Academy Press, Washington, DC, 266 pp.

North, R.C., Rear Admiral, U.S. Coast Guard. 1999. United States House of Representatives, statement before the House Subcommittee on Transportation and Infrastructure. 29 June. 
OSIR (Oil Spill Intelligence Report). 1996. USCG issues final rule on operational measures for single-hull tankers. OSIR 19(30).

Ornitz, B. E. 1997. Prevention through people. International oil spill conference proceedings, pp. 171-176.

Plater, J. B., R. H. Abrams, R. H., W. Goldfarb, and R. L. Graham. 1998. Environmental law and policy: nature, law, and society, West Publishing Group, American Casebook Series. St. Paul, Minnesota, 1229 pp.

US ACE (United States Army Corps of Engineers). 1999. NDC publications and US waterway data compact disc. Water Resources Support Center, Navigation Data Center. Alexandria, Virginia.
USCG NAVCEN (United States Coast Guard Navigation Center). 1999. www.uscg.mil. Alexandria, Virginia.

USCG (United States Coast Guard). 1993. Licensing 2000 and beyond. Technical Report. USCG, Washington, DC.

USCG (United States Coast Guard). 1995. Prevention through people. Quality Action Team report. USCG, Washington, DC, 50 pp.

Woodward, C. 2000. Ocean's end. Basic Books, Perseus Book Group, New York, 300 pp.

Yaffee, S. L. 1982. Pages 65-100 in Prohibitive policy. implementing the federal Endangered Species Act. MIT Press, Cambridge, Massachusetts. 